\title{
Astronomy and the I.G.Y.
}

By JOHN HODGES, Regina

We have been hearing announceents regarding a combined operation scientists all over the world in a Idy of the Earth. This extensive ogramme of research is called the ternational Geophysical Year and 11 begin July 1, 1957. Actually, the €ar" will be 18 months long, allowtime for observing phenomena fich may occur over a period of ne greater than 12 months, and so allowing for overlapping of obrvations from various parts of the orld. Soon we shall be referring this programme as the I.G.Y. as become more familiar through orld-wide publicity with its dramic projects and their results.

This is not the first operation in hich scientists from many countries ve co-operated to gather data and arn more about a particular subject. it it will be the greatest. During is operation, scientists hope to unvel some of the mysteries about e earth, such as its magnetism, its ue size and shape. The phenomenon aurora in our upper atmosphere ill come under close scrutiny. Since e source of these displays probably s deep in the Sun, in learning pout aurora we may learn more pout our nearest star, the Sun.

Man occupies very little of the atospheric envelope, his usual level of cupation being from the surface the earth to the top of the Empire tate Building. A few go deep in ines, or fly fairly high in the lower gions of the atmosphere, but no he knows just what the conditions e "high up". To gain data, rockets ill be sent up to gather samples and dio temperatures, etc. back to earth.

Canada will play a very important art in I.G.Y. The University of
Saskatchewan will be a centre for aurora studies. The base for some cf the rocket launching will be Churchill. Meteor data will be gathered, both by visual methods and by radar, through the National Research Council, Upper Atmosphere Division, Ottawa.

One of the most dramatic events to occur during the I.G.Y. will be the launching of satellites. Man has undertaken to put a sphere 30 inches in diameter, packed with instruments weighing approximately 21.5 pounds, 300 miles above the earth's surface and to keep it there by imparting to it a speed of 17,053 miles an hour in a course parallel to the earth's surface.

The first of these satellites and perhaps the second wll not be visible at Regina's latitude. However, with binoculars you may get a good look at number three, and even without glasses, a few peeks at sunrise or sunset. If you are not fortunate enough to see it the first time, bear in mind that it will rise and set 15 times during 24 hours if it returns over your locality.

Perhaps one of the first benefits of this project to you and me will be what is learned about forecasting weather. We should also like to know whether the earth is warming up, and if so, how fast. These studies will require men to go to the coldest regions of the earth, and many expeditions are already in position. We hope for much from the International Geophysical Year, for we are living in an age that promises to reveal more about the universe we live in than any past age has done. The really interesting point at this time is that more than 40 countries have enlisted the ability of over 5,000 scientists in a co-operative effort to help man take his first step into space.

Contributions to this page or enquiries about astronomy may be sent to John Hodges, 1554 Elphinstcne St., Regina. 